\title{
A educação em saúde na relação usuário-trabalhador no cotidiano de equipes de saúde da família
}

\author{
Health education in the user-worker relationship \\ in the the daily routine of family health teams
}

Elisangela Pinafo ${ }^{1}$

Elisabete de Fátima Polo de Almeida N unes ${ }^{2}$

Alberto Durán González ${ }^{2}$

${ }^{1}$ Setor Enfermagem, Centro de Ciências Biológicas, UniversidadeEstadual do Nortedo Paraná. Rodovia BR 369Km 54,Vila M aria. 86360-000 Bandeirantes PR. elisangelapinafo@ yahoo.com.br ${ }^{2}$ Departamento deSaúde Coletiva, Centro de Ciências da Saúde Universidade Estadual de Londrina.
Abstract The scope of this research was to analyze how the practice of health education occurs in the informal user-worker relationship, and the strategies used for its implementation in routine primary care. It is a qualitative study conducted with two Family Health teams and the data was collected through observation and semi-structured interviews and assessed using discourse analysis. $\mathrm{H}$ ealth education in the informality of professional-user relations occurs in everyday conversations and guidance, and permeates the various issues involving the needs of users. Workers present educational strategies that occur in a non-structured manner, some of which portray a differentiated way of implementing educational practice, though most of these are restricted to the transfer of information, in which employees seek to transfer/inform reinforcing their attitude of imposition and control of know-how they consider to be right. It is necessary to rethink and enhance health education as labor technology, which reveals different processesfor action in health, reorienting the practice into meaningful learning, which promotes change among users, workers, and in the current healthcare model.

Key words Health education, Family health, Human resources in health
Resumo 0 objetivo desta pesquisa foi analisar como ocorre a prática da educação em saúde em momentos informais da relação usuário-trabaIhador, e as estratégias utilizadas para a sua concretização no cotidiano da atenção básica. Tratase de um estudo qualitativo, realizado com duas equipes de Saúdeda Família, sendo os dados coletados por meio de observação e de entrevistas semiestruturadaseavaliados segundo análisedediscurso. A educação em saúde realizada na informalidade das relações profissional-usuário ocorre nas conversas e nas orientações do cotidiano, e permeiam os variados temas que envolvem as necessidades dos usuários. Os trabalhadores apresentam estratégias educativas que se dão de forma não estruturada, al gumas retratam um modo diferenciado de realizar a prática educativa, porém a maioria destas prende- seao repasse deinformações, no qual o trabalhador procura transferir/ informar, reforçando sua atitude de controle e imposição de um saber que julga ser o certo. Torna-senecessário ser repensada evalorizada a educação em saúde como uma tecnologia de trabaIho, querevela diferentes processos deagir em saúde, reorientando esta prática em uma aprendizagem significativa, e que promova mudança para os usuários, trabalhadores, e para o modelo de atenção à saúde vigente.

Palavras-chave Educação em saúde, Saúde da família, Recursos humanos em saúde 


\section{Introdução}

A educação em saúdee suas práticas desenvolveram-se de forma significativa nas últimas décadas, e possuem um espaço prioritário nas ações cotidianas dos serviços de saúde, principalmente na atenção básica devido à sua ênfase em ações preventivas e de promoção da saúde ${ }^{1}$.

A promoção da saúde se distingue da prevenção, no entanto são complementares ao processo saúde-doença e o conteúdo teórico entre estes dois campos se diferencia com mais precisão em relação às respectivas práticas².

0 enfoque da promoção da saúde é mais amplo eabrangente, busca verificar, enfrentar etransformar os macrodeterminantes do processo saúde doença em direção da saúde. A prevenção visa que o indivíduo fique isento das doenças².

Na prática educativa, as ações de promoção da saúde procuram intervir nas condições de vida das pessoas, para que estas sejam dignas e adequadas, auxiliando no processo de tomada de decisão em direção à qualidade de vida eà saúde. Já as ações educativas de cunho preventivo, orientam as ações de detecção, controle e enfraque cimento dos fatores de risco, tendo como foco ações que distanciam ou evitem a doença.

Independentemente do tema abordado durante a prática educativa, o processo de promoção-prevenção-cura-reabilitação é um processo pedagógico que precisa ser explorado no cotidiano do trabalho em saúde, no sentido de que nesta interação educativa tanto o profissional de saúde quanto o usuário aprendem e ensinam ${ }^{3}$.

A prática educativa é indissociável da ação laboral do trabalhador, com vistas a promover mudanças tanto para os usuários quanto para o profissional e para o processo de trabalho em saúde, acreditando no seu potencial em direção à transformação do modelo de saúde vigente.

Alves e Nunes 4 sinalizam que o cotidiano do trabalho em saúde éreconhecido pelos profissionais como uma situação oportuna para a prática da educação, e que toda ação é provida de uma ação educativa, estando presente em todo contato entre o profissional de saúde e o usuário.

Estes momentos de encontros em que a prática educativa acontece são potenciais, que podem mudar efetivamente a forma e os resultados do trabalho em saúde, transformando pacientes em cidadãos, copartícipes do processo de construção da saúde 3 .

Alves ${ }^{5}$ destaca que as práticas educativas podem ser desenvolvidas nos espaços convencionais dos serviços, sendo denominadas como prá- ticas educativas formais, como exemplo a realização degrupos e pal estras educativas, bem como nas ações de saúde cotidianas, denominadas informais, como nos momentos de encontro entre o usuário e o trabalhador de saúde, na realização de orientações ou numa conversa informal.

Desta forma, surgem as seguintes questões: como a edu cação em saúde acontece na atenção básica? Como a sua prática se revela no cotidiano da produção do cuidado?

Analisar a prática da educação em saúde na atenção básica nos permite conhecer como os profissionais operacionalizam o seu conhecimento enquanto instrumento de trabalho, possibilitando nos revelar sua forma de agir na produção do cuidado com base no processo educativo em saúde.

Neste sentido, este trabalho teve como objetivo analisar como ocorre a prática da educação em saúde em momentos informais da relação usuário-trabal hador na realidade vivenciada pela equipe de Saúde da Família (SF), e as estratégias utilizadas para a sua concretização no cotidiano da atenção básica.

\section{Percurso metodológico}

Esteartigo éparte deuma dissertação deM estrado que teve como propósito compreender a educação em saúde no cotidiano da equipe de Saúde da Família ${ }^{6}$.

Trata-se de uma pesquisa qualitativa que foi realizada em um município de pequeno portesituado no norte do Paraná. A população estudada compreendeu os profissionais de saúde de duas equipes de SF, que trabal havam em diferentes unidades de saúde, com áreas de abrangência distintas, sendo uma delas da área rural do município.

Todos os profissionais das duas equipes foram entrevistados e suas práticas foram observadas, totalizando 14 trabalhadores. Dentre as categorias profissionais dos participantes estão: enfermeiras, auxiliares de enfermagem, médicos e agentes comunitários de saúde.

Primeiramente, foi realizada a observação das práticas educativas no cotidiano de trabalho da equipe deSF, que consistiu no acompanhamento de atividades desenvolvidas pelos profissionais. A observação foi realizada pela pesquisadora no ambiente de trabal ho de cada equipe e ocorreu em dias e períodos alternados durante três meses, de abril a junho de 2009. Quanto à observação, foram analisadas as atividades educativas 
realizadas pelos profissionais da equipe de SF às situações apresentadas em seu cotidiano. Utilizou-se um diário de campo (DC) que auxiliou posteriormente na produção de um relatório minucioso das observações.

Logo após a fase de observação, foram realizadas entrevistas com os profissionais de saúde (mês de julho/2009), sendo que as mesmas foram gravadas e posteriormente transcritas. $\mathrm{A}$ entrevista foi conduzida a partir de um roteiro quecontinha, na primeira parte, os dados deidentificação ea experiência profissional com educação em saúde, e na segunda parte, aspectos que contemplaram o desenvolvimento da educação em saúde no cotidiano da equipe de SF.

Os dados foram analisados segundo a metodologia de análise de discurso, tendo como embasamento teórico o referencial de Spink ${ }^{7}$ que possui como foco central o construcionismo social, mostrando ser um caminho para entender a produção de sentidos no cotidiano.

Para análise do corpus da pesquisa foi construído um mapa de associação de ideias para a organização dos dados coletados na observação ena entrevista, possibilitando assim a categorização das respostas a partir dos núcleos de sentido.

Os profissionais entrevistados foram identificados em seus depoimentos por meio de letras iniciais da sua profissão e por números (E1, M 2, $A E 3, A 4 \ldots)$, como forma de garantir o anonimato dos entrevistados. As falas serão apresentadas fazendo parte do texto, em itálico, seguida da indicação do profissional que a pontuou.

Os princípios éticos que nortearam esta pesquisa estão contemplados na resolução 196/96, que regulamenta a pesquisa envolvendo seres humanos ${ }^{8}$, e esta foi aprovada pelo Comitê de ética em Pesquisa da Universidade Estadual de Londrina (UEL) no Paraná.

Da análise do material colhido emergiram as seguintes categorias de análise: A prática informal da educação em saúde na atenção básica e Estratégias educativas informais utilizadas pela equipe de Saúde da Família em suas ações.

\section{Resultados ediscussão}

\section{Caracterização dos sujeitos da pesquisa}

Ao total foram 14 os participantes do estudo, pertencentes a distintas categorias profissionais, sendo duas enfermeiras, dois médicos, quatro auxiliares deenfermagem eseis agentes comunitários de saúde. Oito profissionais trabal havam na
UBS da área urbana, seis na da área rural, sendo 13 do sexo feminino. A faixa etária variou de 22 a 48 anos. Cinco profissionais apresentaram formação Superior e, os demais, Ensino M édio Completo com curso profissionalizante. Todos os entrevistados eram concursados em emprego público para atuação na Saúde da Família.

Os profissionais entrevistados disseram ter experiência anterior no campo da educação em saúde, e esta foi adquirida na atuação na Saúde da Família ao desenvolverem atividades em grupos e palestras educativas. As enfermeiras foram as profissionais que pontuaram desenvolver atividades educativas frequentemente, além deapresentarem experiência na docência, uma na área de enfermagem eoutra na capacitação para ACS. Um dos médicos referiu ter ministrado aulas para pós-graduação em curso de Enfermagem Obstétrica.
A prática da educação em saúde
em momentos informais da relação
usuário-trabalhador

A educação em saúde desenvolvida na informalidade das relações entre o profissional e 0 usuário é realizada por todos os profissionais da equipe de SF. É uma atividade individual (E2), que ocorre de maneira não organizada nem programada (M 1), tanto dentro da unidade de saúde quanto fora, como nas visitas domiciliares (E1), no atendimento da demanda espontânea e da demanda programada. Observou-se que são feitas de diferentes maneiras conforme o cenário local, ocorrendo de forma inerente ao processo de trabalho: desde [o momento de] uma préconsulta, de saber qual éa queixa do paciente, na pós-consulta, na entrega de medicamentos, orientações para exames, em tudo (E1).

Esta forma de condução das atividades educativas foi observada em vários outros estudos realizados na atenção básica, que citaram os diversos espaços e a variedade de tipos de atendimento como palco favorável a estas práticas ${ }^{9-11}$. $\mathrm{N}$ a presente pesquisa, 0 cotidiano da assistência à saúdemostrou-se espaço de ação educativa pelo significado que esta atividade traz para o cuidado em saúde realizado.

Este cotidiano é reconhecido pelos profissionais como uma situação oportuna para a prática da educação em saúde, no qual o mundo do trabal ho constitui-se num amplo espaço de saberes emodos de produção do cuidado, quese materializam em tecnologias de trabal hos utilizadas para produzir saúde ${ }^{2,12}$. 
A finalidade dequalquer ação em saúdeéproduzir 0 ato de cuidar ${ }^{13}$. No presente estudo, 0 profissional percebeu que toda ação em saúde reflete em uma conduta educativa, pois em todo cuidado realizado deve haver um educar aplicado: tudo tem queser devidamente esclarecido, educação em saúde além de cuidar é estar educando para aquilo que você está aplicando (E2).

De acordo com o observado e segundo a percepção dos profissionais entrevistados, a educação em saúde também ocorre de maneira informal nos momentos de encontro e de interação entre o usuário e o profissional de saúde (DC p.32): na verdade, todo dia é praticada a educação em saúde no contato com os pacientes (A4). 0 profissional senteque as práticas educativas concretizam-se numa forma de ação imediata, vivida pelos sujeitos que dela participam.

A presente pesquisa nos mostrou que por meio destas relações e interações entre trabalhadores e usuários, ambos se colocaram na posição de atores/sujeitos com suas subjetividades, produzindo as atividades educativas nos encontros cotidianos, no diálogo e vínculos construídos conforme sua visão de mundo, de sociedade e de saúde.

Existeumaintencionalidadeno processo educativo, mesmo em sua prática informal, pois o profissional procura na conversa cotidiana um meio de comunicação que busque a construção do conhecimento: a partir do momento que você está conversando com alguém, mesmo um diálogo informal, de uma forma ou de outra você está fazendo educação em saúde (E2). Desta forma, a conversa é tida como um meio de trabalhar a educação em saúde, tendo sua ação educativa permeada pela linguagem falada e/ou pelos gestos e demonstrações (AE2) que o trabalhador faz ao buscar a compreensão do usuário.

Praticar a educação em saúde por meio das conversas do cotidiano, parte exatamente de orientações que são realizadas (E2). As orientações são consideradas uma prática, na qual se valoriza o espaço das relações e do diálogo entre usuário etrabalhador no contexto da atenção prestada, tornando-se uma maneira predominante e corriqueira deseeducar/informar o paciente(A5).

A conversa como prática discursiva é compreendida como linguagem em ação, em que o discurso é tomado como ação, pois é tão produtor de realidade quanto qual quer ação concreta ${ }^{7}$. A qual pode ser vista por meio de todo ato que produza um resultado ao paciente, desde a realização de um procedimento que por meio de uma técnica proporciona seu bem estar, bem como uma prática educativa que colabora com a conscientização do usuário na condução de suas necessidades. Desta forma, a conversa/orientação faz-se produtora de uma realidade em ação, ou seja, torna-se uma realidade educativa no trabaIho vivo em ato.

Durante 0 atendimento ao paciente, a conversa é algo extremamente rico e importante no campo da comunicação na vida cotidiana, vinculando a educação aos processos de produção em saúde. Estas conversas permeiam as mais variadas esferas de interação social, e dificilmente pensa-se nas peculiaridades que possam estar presentes nessa forma de comunicação ${ }^{7}$.

No entanto, a relação que se estabelece entre trabal hador e usuário é uma relação hierárquica de passar a informação, controlar, como demonstrado na seguinte fala: ele chega evai verificar a pressão, então a gente pergunta sejá tomou o remédio e vai orientar porque a Pressão Arterial (PA) deleestá alta, porqueeletem queusar a medicação, porque não esta melhorando a pressão com a medicação (AE2). A concepção de educação presente nas orientações observadas ocorre de forma vertical e autoritária, como acontece com as práticas de saúde centradas no modelo médico hegemônico.

0 mesmo resultado foi observado no estudo de Pereira e Servo ${ }^{9}$, na qual a prática educativa estava envolta pel a concepção de educação tradicional ou sanitária, entendida como uma atividade de transmissão de informações. Assim, o profissional de saúde explica ao usuário hábitos e comportamentos saudáveis, cabendo ao mesmo a responsabilidade de mudar e adotar um novo estilo de vida, como se estas mudanças dependessem somente de uma decisão individual, sem considerar o contexto social, econômico em quevive.

As práticas educativas realizadas nos momentos informais ocorrem tanto por iniciativa do profissional quanto do usuário, dependendo da necessidade de compreensão dos fenômenos que ocorrem à sua volta, partindo muitas vezes das inquietações do profissional ou de dúvidas dos usuários, ou seja, se dá durante as conversas estimuladas por perguntas e respostas do cotidiano (DC).

Segundo Spink ${ }^{7}$ as interações comunicacionais que trazem sentido são iniciadas através de perguntas e respostas do cotidiano, e o que as defineéo posicionamento eas manifestações dos sujeitos envolvidos. Semelhante ao encontrado no estudo de Vaz et al. ${ }^{14}$, na presente pesquisa pôde-se verificar que as indagações, os questio- 
namentos, as perguntas e as respostas das conversas do cotidiano são um meio de iniciar uma prática educativa, que procura indagar sobre as necessidades que envolvem o significado do processo saúde-doença por parte do usuário e que muitas vezes é percebida pelo trabal hador.

Estas práticas são desenvolvidas de acordo com o ritmo de trabalho do profissional e da demanda da UBS, podendo acontecer com uma maior disponibilidade de tempo como num dia tranquilo para 0 atendimento, como também pode ficar limitada como num dia tumultuado (AE3). Não se pode deixar de considerar que esta prática depende muito da vontade e de querer fazer a educação em saúde (M 1). A decisão de realizar esta prática é intrínseca a cada sujeito e tem que se considerar que toda atividade recebe influências do mundo circundante como o tempo de atendimento, espaço laboral, concepções/ percepções de saúde, educação, além da influência que outros atores envolvidos exercem direta ou indiretamente na qual idade da ação realizada.

$M$ as, a medida que o profissional observa a progressiva importância conferida à sua prática e os frutos produzidos por ela, percebe a importância desta para si mesmo. Isto pode tornar-se um motivo de estímulo e incentivo quando os sentidos trazidos pela prática educativa são positivos. Deste modo, verifica-se quea vontade de fazer a educação em saúde parte das representações e significados que esta ação traz para o trabal hador. N estes termos, pode-se pensar que um trabalhador consciente da importância da prática educativa é estimulado para desenvolvêla, já o trabalhador que não reconhece a importância e o significado desta, pode não ter vontade de realizá-la.

Outra forma de realizar a educação em saúde na informalidade das ações consiste na sua prática durante as visitas domiciliares, que no PSF é vista como tecnologia de interação no cuidado e instrumento deintervenção, inserção e deconhecimento da realidade de vida da população ${ }^{15,16}$.

Os profissionais da equipe de SF referem-se ao domicílio como um local propício para a abordagem educativa de toda a família (AE4): se a pessoa idosa mora sozinha a gente procura conversar com ela, mas se mora com familiar a gente procura estar conversando com os familiares também (A2). Acompanhando a visita domiciliar de um ACS, este refere que as explicações sobre os cuidados com os idosos ficam mais claras quando realizada no domićlio, tornando mais fácil a sugestão de adaptações dos móveis e tapetes possíveis de serem realizadas (DC). Segundo observações realizadas, estar próximo do ambiente familiar e da dinâmica de suas relações, faz com que o profissional esteja em contato com as necessidades dos usuários para, assim, tentar ajudá-lo a encontrar o melhor caminho para a condução de seus problemas, além das ações educativas se tornarem condizentes com a realidade vivenciada pelos usuários.

A visita domiciliar éfeita em sua maioria pelo $A C S$, sendo que os outros profissionais da equipe pouco executam esta atividade. Para o ACS a visita domiciliar éimportante principalmentetratando-se de sua função: é mais na visita que eu faço as orientações (A4). No entanto, a educação realizada nos domicílios, também como na maioria das vezes, possui limitações restringindo-seà transmissão de informação, controle e na vigilância em saúde com limitada resolubilidade: ...eu semprepergunto se tevecasos de diarréia, de vômito. Eu passo informação se a pessoa fez o preventivo, a respeito de medicamentos, hipertensos e diabéticos se el es estão controlando, se eles tomam esses medicamentos corretamente, se verificam a pressão. Passo informação a respeito de doenças como éfeito nas campanhas como a de hanseníase, de tuberculose, oriento em caso de aparecimento de manchas ou de tosse (A6).

No que tange as reflexões sobre a visita domiciliar, esta atividade éuma maneira de se contrapor ao modelo hegemônico desaúde, pois dispõe de condições propícias para mudan ças ${ }^{17}$. $\mathrm{N} 0$ entanto, o quese observa éque muitas vezes ainda continua sendo médico centrada, voltada para a queixa biológica, com o enfoque de educação pela transmissão/informação, no modelo curativista. Há uma expectativa por parte da população de que o profissional de saúde solucione os seus problemas, e isto leva o trabalhador a adotar esta conduta por entender que desta forma, informando, estará ajudando o usuário nas necessidades apresentadas.

0 profissional também reconhece a amplitude dos problemas trazidos pelo usuário: a gente procura saber qual é o problema deles, só que a gente não só enfrenta problemas da saúde, a gente encontra desabafos e outros problemas (A2).

De maneira geral, a equipe de enfermagem encontra-se constantemente em contato com a população, tanto dentro da UBS quanto nas visitas domiciliares, sendo os profissionais responsáveis pelo andamento da unidade e os mais demandados pela população que solicitam os seus serviços, suas orientações.

Identificou-seno trabalho médico quea educação em saúde é real izada prioritariamente du- 
rante 0 atendimento ao usuário nas consultas médicas, tendo como foco educativo a patologia do usuário: ....a gente nas consultas, tenta explicar o que ele têm, 0 que nós vamos fazer, quais são os exames necessários e quando confirmado o diagnóstico, o tratamento e o porquê daquele tratamento (M 2).

De maneira geral, pode-se perceber em toda equipe de SF, que suas ações educativas realizadas nos momentos informais foram permeadas por vários fatores que limitaram e determinaram a forma de condução das mesmas. Dentre estes fatores pode-se citar o tempo, no qual a existência ou não deste foi determinante na maneira de se realizar a prática educativa, ora como transmissiva/controladora, ora como possibilidade de se criar uma atmosfera potencializadora deindivíduos reflexivos eautônomos, como também os fatores intrínsecos de cada profissional/ sujeito, suas concepções e percepções sobre educação foram determinantes na postura e atitudes de educar em saúde.

Estratégias educativas informais utilizadas pela equipe de Saúde da Família em suas ações

Os profissionais da equipe de SF sentem a necessidade de desenvolver estratégias educativas e formas de abordagem para conseguir prender a atenção (AE3) do usuário, almejando o seu entendimento ecompreensão da importância do tema discutido. No entanto, estas estratégias são realizadas, muitas vezes, de forma não estruturada, segundo suas experiências prévias, sua visão de mundo e de sociedade.

Para isto o trabalhador diz que precisa falar diversas vezes (AE4) com o usuário, demonstrando a necessi dade de estar sempre relembrando, falando, por que algumas coisas ele vai absorver (E2), além de ressaltar a importância de sua insistência e persi stência na tar efa de educar: ...quando você para pra explicar ele te escuta só que você tem que bater sempre na mesma tecla, insistir, não é uma sementinha que você planta e funciona, tem que ficar regando, cobrando, cuidando se não, não vai pra frente (M 1).

0 profissional reconhece que o usuário presta aten ção no queeleapresenta. No entanto, percebe-se uma ausência de escuta por parte do trabalhador, que insiste numa postura de repetição como estratégia de comunicação, na tentativa de domesticar e treinar, não valorizando o encontro com o usuário como uma oportunidade de aprendizado. Além disso, apresenta um discurso ambivalente que vê a educação em saúde como uma ação que precisa ser mantida, cuidada, porém reforça o caráter de repetição e cobrança para que o paciente faça o que 0 trabal hador concebe como correto, não como um momento de diálogo, de negociação.

A integralidade das ações em saúde se dá pelo compromisso dos profissionais de escutar atenta ecuidadosamente os usuários para assim identificar suas necessidades de saúde, para isso o diálogo deve se tornar uma comunicação de ida e volta, sem bloqueios ${ }^{10,18}$.

Em sua prática, os profissionais também deram sinais de desenvolverem estratégias de cobrança, instigando um certo "policiamento" ou controle das atitudes dos indivíduos: eu olho carteirinha de vacinação porque tem mães que deixam as vacinas atrasadas, então tem que pegar no pé, tem que orientar e cobrar (A6). 0 presente discurso reflete uma visão educativa pautada no controle, cobrança do usuário, na transmissão e repetição da informação. Pode-se inferir que esta postura encontra-se associada à formação deste profissional, que reproduz sua vivência educativa, pois se verificou durante o período de observação o compromisso das equipes com os usuários, preocupando-se em transmitir orientações que julgavam necessárias para a comunidade.

Estudo realizado em Cajuri-MG, descreveu esta atitude dos ACS como de "polícia sanitária", que segundo Gomes et al. ${ }^{19}$ esta abordagem puramente biológica não consegue preparar os profissionais para lidarem com toda a complexidade do processo saúde-doença-adoecimento, gerando insegurança e atitudes incoerentes com 0 funcionamento do atual sistema de saúde.

0 caráter normatizador e autoritário desta cobrança demonstra uma relação assimétrica entre o profissional e o usuário, sinalizando uma concepção bancária ondeo profissional éo sujeito do processo e o usuário um simples objeto ${ }^{20}$.

Os trabalhadores também demonstraram utilizar estratégias coercitivas para convencer 0 usuário a realizar o que, segundo suas concepções, era a melhor conduta: na campanha de vacina, tem muito idoso que não quer tomar a vacina, daí a gentefala quese eles não tomarem a vacina, o governo vai tirar a aposentadoria, eeles acreditam e tomam (AE2). Esta postura aponta para uma atitude de não reconhecimento da autonomia do usuário em decidir o que é melhor para si, não o considerando responsável por suas decisões, etampouco contribui para ampliar o diálogo entre trabalhador/usuário e ampliar a capacidade de análise dos sujeitos. Agindo desta 
forma, o profissional pode perder a credibilidade em seu trabalho e suas ações educativas não serem bem aceitas pela população.

Nesta postura "coercitiva" demonstrada pela atitude de al guns profissionais, verifica-se que 0 trabalhador não favorece a autonomia dos sujeitos em decidir sobre sua saúde, assim a educação segueum modelo que produz indivíduosque não são críticos e que podem ser manipulados por outro ${ }^{20}$.

No entanto, os trabalhadores reconhecem que a cobrança deve existir em dose adequada, pois se chegarem somente impondo sua visão ao usuário, o profissional perde a credibilidade de seu trabalho educativo: porqueédifícil vocêchegar cobrando, eu quero isso, é assim que tem que ser, eles não aceitam (A4).

Durante a prática educativa, o trabalhador demonstrou ter um cuidado maior com o grau de instrução do usuário, pois os profissionais de saúde trabal ham com pessoas de variadas escolaridades, desde analfabetos à especialistas, desta forma, o trabalhador procura utilizar uma linguagem simples, acessível e de fácil compreensão (M 2), por considerar que para o usuário entender, você tem que falar a língua deles (A4). Referem utilizar termos populares (AE4), exemplos (E1), e partem da realidade do usuário (A3). Ao observar 0 atendimento realizado por uma auxiliar de enfermagem durante a verificação da PA, e entrega de medicamento a um paciente hipertenso, a auxiliar utilizou vocabulário que faz parte do repertório da população explicando de maneira a facilitar a compreensão do paciente, deixando- 0 à vontade, além de certificar o seu entendimento em relação ao assunto discutido (DC).

No processo comunicativo, o profissional precisa levar em conta o contexto de sua ocorrência, caso contrário, seu sentido pode ser pre judicado, afetando a compreensão do usuário. A forma de abordagem utilizando uma linguagem simples é realizada pela mai oria dos trabal hadores. Entretanto, no processo educativo dos profissionais de nível superior, como médicos e enfermeiros, estes utilizam também uma linguagem científica para a explicação dos diagnósticos ou problemas de saúde, mas em seguida, foi observado que procuram falar a mesma coisa de uma maneira simples para melhor compreensão do usuário. No entanto, por mais que o trabaIhador avance em direção a uma abordagem que reconheça o contexto da prática educativa ainda continua posicionando-se como detentor do saber, responsável pela transmissão desta informação que é sua e não do outro.
Outra estratégia foi a abordagem do usuário de forma descontraída (AE2), desenvolvida na conversa cotidiana no qual o profissional aproveita para reforçar as orientações básicas e mais importantes (A5), sem apresentar um linguajar excessivamente técnico. Para Freire ${ }^{21}$ "educar exige alegria e esperança", e que os momentos de alegria são tidos como oportunos para uma maior apreensão dos conteúdos aplicados na prática educativa.

Tendo em vista as estratégias utilizadas de forma intuitiva na prática educativa dos profissionais estudados, pode-se perceber que quando a equipe contorna os diversos obstáculos apresentados, os temas abordados permeiam o universo do trabalho da $A B$ e focam a promoção da saúde, preven ção de agravos, cura de enfermidades e reabilitação do paciente, porém ainda existe um destaque maior para as práticas cujos temas estão voltados para as patologias. N ota-se que quanto maior a expertise técnica do profissional, maior o direcionamento para os temas ligados a patologias com caráter prescritivo, pouco informativo e verticalizado.

\section{Tecendo al gumas considerações}

Tendo em vista a amplitudee a complexidade da educação em saúde realizada na relação profissional-usuário, esta é produzida a partir do agir cotidiano, que reflete a produção de sentidos trazida pelas relações das práticas de cuidado, na qual as estratégias educativas utilizadas se dão de forma não estruturada, mas com intencionalidade, retratam um modo diferenciado de realizar a prática educativa, porém a maioria prendese ao repasse de informações.

0 discurso dos trabalhadores mostrou-se, de certa forma, mais avançado que as práticas educativas, no entanto, não se pode deixar de considerar que este trabal hador reproduz o modelo de educação que Ihe foi ensinado, além do processo de trabalho em saúde fortalecer esta postura quando valoriza mais a prática curativa, voltada ao atendimento à demanda do que às práticas de promoção da saúde.

M ediante o conhecimento dos trabal hadores e de suas práticas no cotidiano das equipes deSF, a produção de saberes e práticas no SUS devem ir ao encontro da integralidade no atendimento ao usuário, contrapondo-seao modelo hegemônico com olhar fragmentário e reducionista. Deve-se, portanto, considerar o usuário em sua totalidade como sujeito biopsicossocial, com 
autonomia em suas escolhas e copartícipe da construção da assistência à saúde.

Vale lembrar a necessidade de maior investimento na educação permanente dos trabalhadores de saúde como instrumento propício para mudanças, implementações e reforço das ações educativas realizadas nos momentos de interação usuário-trabalhador e em seus discursos durante 0 atendimento em saúde.

A educação em saúde deve ser repensada e valorizada como uma tecnologia de trabalho, que revela diferentes processos de agir em saúde, reorientando esta prática, tomando como princípios os preceitos do SU S e uma aprendizagem significativa, para que promova mudança na vida dos usuários e dos trabal hadores, assim como na realidade do modelo de atenção à saúde vigente.

\section{Colaboradores}

E Pinafo, EFPA Nunes e AD González participaram igual mente de todas as etapas de elaboração do artigo.

\section{Referências}

1. Gazzinelli FM, Gazzineli A, Reis DC, Penna CMM . Educação em saúde: conhecimentos, representações sociais e experiências da doença. Cad Saude Publica 2005; 21(1):200-206.

2. Buss PM. Uma introdução ao conceito de promoção da saúde. In: Czeresnia D, organizador. Promoção da saúde: conceitos, reflexões, tendências. 2āe ed. rev. ampl. Rio de Janeiro: Fiocruz; 2009. p. 19-42.

3. Albuquerque PC, Stotz EM. A educação popular na atenção básica à saúde no município: em busca da integralidade. Interface - Comun. Saúde Educ 2004; 8(15):259-274.

4. Alves VS, Nunes MO. Educação em Saúde na atenção médica ao paciente com hipertensão arterial no Programa Saúde da Família. Interface - Comun. Saúde Educ 2006; 10(19):131-147.

5. Alves VS. Um modelo de educação em saúde para - Programa Saúde da Família: pela integralidade da atenção e reorientação do modelo assistencial. Interface - Comun. Saúde Educ 2005; 9(16):39-52.

6. Pinafo E. Educação em saúde: 0 cotidiano da equipe de saúde da família [dissertação]. Londrina: Universidade Estadual de Londrina; 2010.

7. Spink MJ, organizadora. Práticas discursivas e produção de sentidos no cotidiano: aproximações teóricas e metodológicas. 3a ed. São Paulo: Cortez; 2004.

8. Brasil. Resolução $n=196 / 96$ de 10 de outubro de 1996. Aprova as diretrizes e normas regulamentadoras de pesquisas envolvendo seres humanos. Diário Oficial da União 1996; 10 out.

9. Pereira APCM, Servo MLS. A enfermeira e a Educação em Saúde: estudo de uma realidade local. Rev Baiana Saúde Pública 2006; 30(1):7-18.

10. Sales FMS. Ações de educação em saúde para prevenção e controle da dengue: um estudo em I caraí, Caucaia, Ceará. Cien Saude Colet 2008; 13(1):175184.

11. Silva CC, Silva ATM C, Lonsing A. A integração e articulação entre as ações de saúde e de educação no programa de Saúde da Família - PSF. Rev Eletrônica Enferm 2006; 8(1):70-74.

12. M erhy EE, Franco TB. M apas analíticos: um olhar sobre a organização e seus processos de trabalho. [site na Internet]. [acessado 2010 jan 21]; [cerca de 22 p.]. Disponível em: http://www.uff.br/saude coletiva/professores/merhy/indexados-07.pdf

13. M erhy $E E$, M iranda Júnior $H$, Rimoli J, Franco TB, Bueno WS. 0 trabalho em saúde: olhando e experienciando o SUS no cotidiano. 3a ed. São Paulo: Hucitec; 2006.

14. Vaz MRC, Sena J, Marins SR, Rubira LT, Santos LR, Cabreira GO, Couto ZFS. Educação e produção de saúde: um estudo da enfermagem de saúde coletiva no extremo sul do Brasil. Texto Contexto Enferm 2003; 12(1):59-67.

15. Giacomozzi CM, Lacerda MR. A prática da assistência domiciliar dos profissionais da estratégia de saúde da família. Texto Contexto Enferm 2006; 15(4):645-653.

16. Lopes WO, Saupe R, Massaroli A. Visita domiciliar: tecnologia para o cuidado, o ensino e a pesquisa. Ciênc Cuid Saúde 2008; 7(2):241-247.

17. Albuquerque ABB, Bosi M LM. Visita domiciliar no âmbito da Estratégia Saúde da Família: percepções de usuários no M unicípio de Fortaleza, Ceará, Brasil. Cad Saude Publica 2009; 25(5):1103-1112.

18. Cecílio LCO. As necessidades de saúde como conceito estruturante na luta pela integralidade e equidade na atenção em saúde. In: Pinheiro $R, M$ attos RA, organizadores. Os sentidos da integralidade na atenção e no cuidado à saúde. Rio de Janeiro: IMS Abrasco; 2001. p. 113-26.

19. Gomes KO, Cotta RMM, Cherchiglia ML, Mitre SM, Batista RS. A práxis do agente comunitário de saúde no contexto do Programa Saúde da Família: reflexões estratégicas. Saúde Soc 2009; 18(4):744-755.

20. Freire P. Pedagogia do Oprimido. 47 a ed. Rio de Janeiro: Paz e Terra; 2005.

21. Freire P. Pedagogia da autonomia: saberes necessários à prática educativa. São Paulo: Paz e Terra; 2008.

Artigo apresentado em 31/03/2011

Aprovado em 09/04/2011

Versão final apresentada em 16/09/2011 